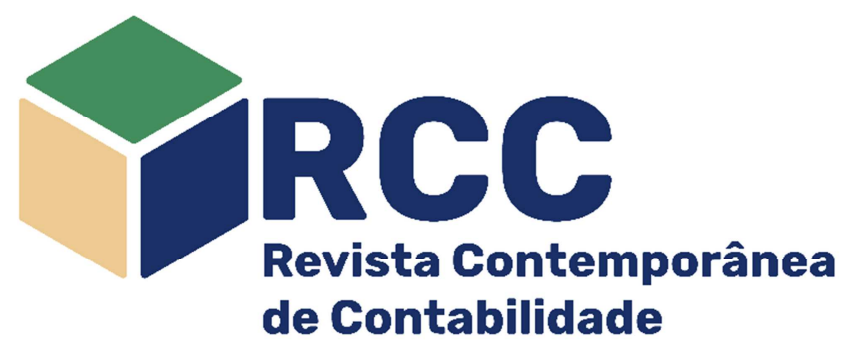

\title{
Remuneração do Chief Executive Officer (CEO) e criação de valor em empresas brasileiras listadas no IBRX 100
}

\author{
Chief Executive Officer (CEO) compensation and value creation in Brazilian companies listed on the \\ IBRX 100
}

\begin{abstract}
Remuneración del Chief Executive Officer (CEO) y creación de valor en empresas brasileñas que cotizan en el IBRX 100
\end{abstract}

Natália Garcia de Oliveira Doutoranda em Controladoria e Contabilidade (UFMG) Professora do Instituto de Ciências Sociais Aplicadas (UNIFAL), Varginha/MG - Brasil nataliaoliveira.unifal@gmail.com https://orcid.org/0000-0001-7177-9750 (1)
Laís Karlina Vieira* Doutoranda em Controladoria e Contabilidade (UFMG) Professora do Departamento de Ciências Gerenciais e Humanas (IFMG), Bambuí/MG - Brasil lais.vieira@ifmg.edu.br https://orcid.org/0000-0002-5484-1580 (1)

Jacqueline Veneroso Alves da Cunha Doutora em Controladoria e Contabilidade pela FEA (USP) Professora Associada do Departamento de Ciências Contábeis (UFMG), Belo Horizonte/MG - Brasil jvac@face.ufmg.b https://orcid.org/0000-0003-2522-3035 (D)

Endereço do contato principal para correspondência* Fazenda Varginha - Rodovia Bambuí/Medeiros - Km 05, CEP: 38900-000, Bambuí/MG - Brasil

\section{Resumo}

Este estudo teve como objetivo analisar a relação entre a remuneração dos CEOs e a criação de valor em empresas brasileiras listadas no IBRX 100. Para tal, contemplou-se o conceito de criação de valor a partir da utilização de medidas que incorporam o custo de oportunidade das empresas, quais sejam: Economic Value Added (EVA) e Market Value Added (MVA). O período em análise foi de 2015 a 2019, com uma amostra de 75 empresas. Para testar as hipóteses, utilizaram-se modelos de regressão linear múltipla, estimados pelo Método dos Momentos Generalizado Sistêmico. Os resultados indicam que o EVA e o MVA impactam na decisão de aumentar ou diminuir a remuneração dos CEOs. Portanto, os achados desta pesquisa podem indicar um alinhamento entre a política de remuneração das empresas analisadas e a criação de valor das organizações, amenizando os conflitos de interesse entre agente e principal.

Palavras-chave: Remuneração; Economic Value Added; Market Value Added; Custo de Oportunidade

\begin{abstract}
This study aimed to analyze the relationship between CEO compensation and value creation in Brazilian companies listed on the IBRX 100. To this end, the concept of value creation was considered through the use of measures that incorporate the opportunity cost companies, namely: Economic Value Added (EVA) and Market Value Added (MVA). The period under analysis was from 2015 to 2019, with a sample of 75 companies. To test the hypotheses, we used multiple linear regression models, estimated by the System Generalized Method of Moments. The results indicate that EVA and MVA impact the decision to increase or decrease CEO compensation. Therefore, the findings of this research may indicate an alignment between the compensation policy of the companies analyzed and the value creation of organizations, alleviating the conflicts of interest between agent and principal.

Keywords: Compensation; Economic Value Added; Market Value Added; Opportunity cost

\section{Resumen}

Este estudio tuvo como objetivo analizar la relación entre la compensación de los directores ejecutivos y la creación de valor en las empresas brasileñas que cotizan en el IBRX 100. Para ello, se consideró el concepto de creación de valor mediante el uso de medidas que incorporan el costo de oportunidad de las
\end{abstract}


empresas, a saber: Economic Value Added (EVA) y Market Value Added (MVA). El período bajo análisis fue de 2015 a 2019, con una muestra de 75 empresas. Para probar las hipótesis, utilizamos modelos de regresión lineal múltiple, estimados por el Método de Momentos Generalizados Sistémicos. Los resultados indican que EVA y MVA afectan la decisión de aumentar o disminuir la compensación del CEO. Por tanto, los hallazgos de esta investigación pueden indicar un alineamiento entre la política retributiva de las empresas analizadas y la creación de valor de las organizaciones, aliviando los conflictos de interés entre agente y principal.

Palabras clave: Remuneración; Economic Value Added; Market Value Added; Costo de oportunidad

\section{Introdução}

A crise financeira global de 2008 colocou a remuneração dos executivos em destaque, devido à detecção de um fraco vínculo entre remuneração e desempenho (Bussin \& Modau, 2015). Muitas críticas foram realizadas às organizações e aos comitês, em virtude de aumentos na remuneração dos executivos diante de resultados financeiros decepcionantes (Lindqvist \& Grunditz, 2004). Quanto a isso, a literatura acadêmica sobre teoria da agência e remuneração de executivos argumentou que a remuneração dos Chiefs Executives Officers (CEO) deve estar alinhada ao desempenho empresarial (Holmstrom, 1979, Grossman \& Hart, 1983). Sob a lente da teoria da agência, os contratos de remuneração precisam ser elaborados para alinhar os interesses dos gestores (agentes) com o dos acionistas (principal). Adicionalmente, uma forte relação entre a remuneração dos executivos e o desempenho pode resultar na seleção e retenção de gerentes mais produtivos (Raithatha \& Komera, 2016).

No cenário acadêmico vários trabalhos analisaram a remuneração dos executivos e a sua relação com o desempenho empresarial. A literatura sobre o tema se concentra nas economias anglo-saxônicas, dessa forma, poucas pesquisas foram realizadas nos mercados emergentes (Raithatha \& Komera, 2016). Destacou-se que os CEOs receberam salários surpreendentes, apesar de grandes problemas enfrentados nas empresas, indicando a necessidade de alinhar a remuneração ao desempenho (Colvin, 2008). Porém, os CEOs são executivos altamente qualificados, possuem competências significativas de liderança e são vistos como um recurso escasso, sendo incentivados por meio de estruturas de remuneração, a permanecerem na organização, desde que, trabalhem para impulsionar o desempenho (Bussin \& Modau, 2015).

A maioria dos estudos que investigam a relação entre remuneração e desempenho utilizam medidas tradicionais a partir de dados contábeis, tais como: i) o retorno sobre o ativo $(R O A)$; e ii) o retorno sobre o patrimônio líquido ( $R O E$ ) (Fatemi et al., 2003). Essas medidas, embora amplamente utilizadas, apresentam falhas, pois não refletem o risco envolvido para uma empresa, considerando o custo do capital próprio, além disso, podem ser propensas a manipulações (Wet, 2012).

Nessa perspectiva, pesquisas sugeriram duas medidas adicionais para investigar a relação entre a remuneração dos executivos e as medidas de desempenho da organização ajustadas ao risco, são elas: o Economic Value Added (EVA) e Market Value Added (MVA) (Bussin, 2015; Wet, 2012). Os trabalhos de Stewart (1991) e Stern (1993) introduziram o conceito de EVA e MVA como medidas superiores para o desempenho corporativo. O EVA é uma medida de desempenho interna, ajustada ao risco, que incorpora o Custo Médio Ponderado de Capital (CMPC) e produz um resultado positivo quando a empresa obtém retornos operacionais após impostos, excedentes ao custo de capital. Por outro lado, o MVA é a diferença entre o valor de mercado da companhia e o capital nela investido (Santos \& Watanabe, 2005). Ressalta-se que o $M V A$ é afetado não apenas pela geração do $E V A$, mas também, por fatores externos capazes de influenciar o preço das ações, sobre o qual as empresas não possuem controle (Wet, 2012).

A partir dos estudos de Fatemi et al. (2003), Wet (2012), Kruger e Petri (2014), Lunardi et al. (2017) observa-se que o EVA e o MVA são medidas adequadas para mensurar a maximização de valor aos acionistas. Sendo assim, é relevante que as pesquisas busquem relacionar a remuneração dos executivos a medidas que alinhem os interesses dos acionistas e gestores. Com base nessas considerações, surge a seguinte questão: qual a relação entre a remuneração dos CEOs e a criação de valor em empresas brasileiras? O objetivo consiste em investigar a relação entre a remuneração dos CEOs e a criação de valor em empresas brasileiras listadas no IBRX 100.

Esta pesquisa pretende contribuir para ampliar a literatura acerca da remuneração dos CEOs no Brasil de forma empírica. Os resultados podem fornecer compreensões sobre a existência de relação entre a remuneração dos CEOs e o desempenho empresarial. Para as empresas e sociedade, as discussões proporcionam insights sobre a importância de estabelecer pacotes de remuneração de forma justa e eficiente, auxiliando no processo de criação de valor para as empresas e mitigação dos conflitos de agência. Uma vez que é preciso integrar de maneira consciente a remuneração com estratégias de geração de valor sustentável em longo prazo nas empresas (IBGC, 2018).

Este estudo se difere das pesquisas nacionais por incorporar medidas de criação de valor, sejam elas: o EVA e o MVA. Em adição, foram incorporadas variáveis para controlar fatores que podem interferir na remuneração dos CEOs quais sejam: características observáveis dos CEOs e do conselho de 
administração (idade, gênero, formação), varáveis de governança (dualidade de funções, tamanho do conselho de administração e conselho fiscal, auditoria por Big Four), tamanho da empresa e variação econômica (Ozkan, 2011; Bugeja et al. 2012; Vieito \& Khan, 2012; Bussin \& Modau, 2015; Lin et al., 2013; Cunha et al. 2016; Lopes et al. 2017; Smirnova \& Zavertiaeva, 2017).

\section{Referencial Teórico}

\subsection{Remuneração de Executivos}

Nas economias modernas a maior parte das empresas se caracteriza pela separação entre propriedade e controle. Essa separação resulta em um conflito de interesses entre gestores e acionistas. Os acionistas não possuem elementos suficientes para monitorar as ações dos administradores, o que gera uma tendência por parte dos gestores de maximizar o seu próprio bem-estar (Berle \& Means, 1932). A partir deste conflito, surge a governança corporativa, com a finalidade de mitigar os problemas de agência auxiliando na elaboração dos pacotes de remuneração (Murphy, 2009). O conselho de administração é o órgão responsável pelo monitoramento da alta gestão em uma empresa e exerce papel fundamental na definição da remuneração do CEO (Finkelstein \& Hambrick, 1988; Lin \& Lin, 2014). Assim, aumentar a independência do conselho pode melhorar a governança corporativa, evitando que gerentes recebam salários mais altos sem justificativas plausíveis (Guthrie et al., 2012).

A teoria da agência sugere que uma das formas de alinhar os interesses dos gestores com os interesses dos acionistas é a partir da vinculação dos contratos de remuneração ao desempenho empresarial, ou seja, para que os diretores possam direcionar suas ações em favor dos acionistas, é necessário que a sua remuneração esteja alinhada ao desempenho (Firth, et al., 2006; Chhaochharia \& Grinstein, 2009). Ademais, dois fatores devem ser considerados na remuneração dos CEOs, são eles: i) o mercado, mercado de trabalho gerencial, produtos marginais de CEOs, tamanho da empresa, desempenho empresarial e capital humano; ii) o poder e as preferências do conselho de administração e do CEO (Finkelstein \& Hambrick, 1988).

A política de remuneração é entendida como um mecanismo capaz de alinhar os interesses entre gestores e acionistas. Logo, os pacotes de remuneração são vistos como um importante instrumento para a mitigação de conflitos de interesse. Porém, a remuneração dos executivos é um assunto complexo e controverso. Alguns estudos argumentam que altos pacotes de remuneração são resultado de gerentes com elevado poder e autonomia para definirem o seu próprio pagamento. Uma outra corrente defende que as altas remunerações decorrem de uma contratação ótima em um ambiente competitivo com a presença de talentos gerenciais (Frydman \& Jenter, 2010; Ozkan, 2011).

O poder gerencial e as forças do mercado podem ser fatores importantes na remuneração dos CEOS. De fato, é relevante compreender como as empresas elaboram os pacotes de remuneração e se, de fato, existe vínculo entre remuneração e desempenho (Frydman \& Jenter, 2010). Pois o sistema de remuneração, quando mal elaborado, tende a fazer parte de um problema de agência, podendo estar baseado em indicadores que prejudicam a visão do principal. Assim, o desenho da remuneração precisa ser alinhado com os objetivos definidos entre as partes do contrato, ser bem estruturado e possuir relação com indicadores de desempenho futuro da empresa (Bebchuck \& Spamann, 2010; Souza et al., 2017).

\subsection{Criação de valor}

Em um ambiente dinâmico e competitivo que caracteriza o mundo empresarial, se torna salutar que as empresas disponham de uma medida adequada para aferir o desempenho econômico-financeiro e conhecer a qualidade da gestão dos negócios. Desse modo, a avaliação da performance empresarial se tornou um dos temas amplamente estudados no campo de finanças e controladoria. Nas pesquisas tradicionais, a ênfase se concentra nas medidas de desempenho como: o Retorno sobre o Ativo (ROA) e o Retorno sobre o Patrimônio Líquido (ROE) (Santos \& Watanabe, 2005).

No entanto, diante da dificuldade em consolidar uma medida capaz de mensurar adequadamente 0 desempenho empresarial, surgiu o Economic Value Added (EVA) que consiste em uma técnica capaz de estimar a criação de valor econômico em uma empresa. A medida foi desenvolvida pelos consultores da Stern Stewart Co. com o objetivo de fornecer incentivos a sua utilização, assim, algumas empresas passaram a adotá-la no processo decisório, vinculando-a à remuneração dos gestores (Tortella \& Brusco, 2003).

O EVA é calculado a partir do lucro operacional após impostos (NOPAT), subtraindo o custo de capital. Apesar de toda retórica positiva em torno do EVA e de todos os benefícios enfatizados pela Stern Stewart and Co, e outros autores, existem estudos que questionam a sua eficácia. A literatura produziu resultados controversos. Alguns estudos descobriram que o EVA aumenta o valor para os acionistas (Stewart, 1991; Stern, Stewart \& Chew, 1998; Pettit, 2000; Tortella e Brusco (2003). Por outro lado, estudos observaram uma correlação positiva e significativa entre o EVA e o MVA (Walbert, 1994; Kruger, 2012). 
O EVA é defendido como um critério de criação de valor, pois se trata de uma medida real do grau de sucesso de uma empresa, cuja administração é responsável por sua maximização (Stewart, 1991). Pode ser considerada uma medida superior aos lucros contábeis e amplamente aceita pelos proprietários e gestores, ao reconhecer o custo ponderado do capital e os riscos empresariais. Não obstante, o EVA apresenta limitações, a principal está relacionada à utilização do sistema tradicional de contabilidade que produz dados limitados, dificultando a obtenção do verdadeiro EVA. Embora existam desafios, é possível implementar o EVA de forma bem-sucedida (Shil, 2009).

O conceito de EVA auxilia na compreensão do processo de criação de valor. A partir de sua utilização, é possível realizar as seguintes ações: i) aumentar a receita operacional dos ativos existentes, reduzindo custos ou aumentando as vendas; ii) reduzir o custo de capital por meio da alteração do mix de financiamentos; iii) reduzir o montante de capital vinculado aos projetos existentes sem afetar de forma significativa o resultado operacional, reduzindo o investimento em capital de giro e vendendo ativos não utilizados. O cenário ideal seria a utilização do EVA com outras métricas, assim, as decisões podem ser tomadas de forma assertiva (Damodaran, 2002; Shil, 2009). Neste trabalho, optou-se por utilizar o EVA em conjunto com o MVA. Essa abordagem foi a mesma utilizada por Wet (2012), ademais existe uma base teórica que ressalta a importância do EVA e do MVA para medir o retorno dos investimentos e a geração de valores aos acionistas, servindo como indicativos preditivos para a gestão empresarial (Kruger \& Petri, 2014).

O Market Value Added (MVA) é uma ferramenta conceitual, também elaborada pela Stern Stewart Co para aferir o quanto a administração agrega de valor ao capital investido na companhia, ou seja, mensura a diferença que os investidores estariam dispostos a pagar em relação ao patrimônio da empresa, a partir de uma comparação entre o valor de mercado (por quanto o acionista poderia alienar suas ações) ao valor patrimonial da empresa (capital social). Sempre que o valor de mercado for maior, o MVA será positivo, o que significa criação de valor aos acionistas, por parte da administração (Camargos, 2008).

O objetivo primário das empresas é maximizar a riqueza dos acionistas. A maximização ocorre a partir da diferença entre o valor de mercado e o montante investido na empresa. Assim, o MVA é o valor presente de todos os EVAs futuros (Stern, 1993). O MVA é influenciado pelo EVA e por fatores externos capazes de influenciar o preço das ações. No entanto, acredita-se que empresas com EVAs positivos e crescentes, de forma consistente, terão possibilidade de maximizar o seu MVA a longo prazo (Brigham \& Gapenski, 1994; Ehrbar, 1998). Embora o EVA e o MVA apresentem correlações entre si, tratam-se de medidas distintas. O EVA é uma medida baseada na contabilidade e avalia o desempenho empresarial em um determinado período. Por outro lado, o MVA é gerado a partir de dados do mercado, incorporando expectativas de resultados futuros (Ramana, 2005).

A partir do advento de medidas capazes de mensurar a criação de valor aos acionistas é possível que algumas empresas optem por vincular os pacotes de remuneração dos executivos à criação de valor. Assim, as medidas que captam de forma mais adequada o desempenho empresarial são o EVA e o MVA. $O$ EVA leva em consideração o custo médio ponderado de capital e o MVA pode ser obtido a partir do valor de mercado das ações. Ademais, do ponto de vista estratégico, não há dúvidas de que um foco voltado para o futuro, baseado na criação de valor para o acionista e na incorporação do risco, consubstanciado no EVA e MVA, é essencial para uma sólida política de remuneração dos executivos (Wet, 2012).

\subsection{Desenvolvimento das Hipóteses}

Estudos anteriores abordaram a relação entre remuneração de executivos e o desempenho empresarial, por meio da utilização de medidas tradicionais e não tradicionais. Adicionalmente, alguns autores optaram pela utilização de variáveis de controle relacionadas a características individuais dos CEOs, tamanho da empresa e mecanismos de governança corporativa como fatores que podem influenciar a remuneração.

Fatemi et al. (2003) trabalharam com uma amostra de empresas domésticas e globais no período de 1992 a 1995. Os autores identificaram que a remuneração dos executivos está relacionada positivamente ao MVA e, em menor grau, ao EVA. O MVA foi um determinante da remuneração dos executivos. Além disso, o EVA e o MVA foram considerados os melhores preditores de variação transversal nos salários dos altos executivos, quando comparado a medida de desempenho tradicional (ROA).

O estudo de Ozkan (2011) teve como objetivo examinar a ligação entre a remuneração do CEO e o desempenho empresarial. Os autores empregaram um painel composto por 390 empresas no período de 1999 a 2005. A proxy utilizada para mensurar o desempenho foi o $Q$ de Tobin. Adicionalmente, foram incluídas remuneração em dinheiro (salário e bônus) e opções de ações (opções de ações e planos de incentivos). Além disso, os autores optaram por controlar variáveis para governança corporativa. Os achados indicaram que $\circ Q$ de Tobin não possui impacto significativo sobre a remuneração dos $C E O$ s.

Wet (2012) estudou a relação entre a remuneração dos executivos de empresas cotadas na África do Sul no período de 2006 e 2010. As medidas utilizadas foram: EVA, MVA, ROA e ROE. Os resultados apontaram uma relação significativa entre a remuneração dos executivos, o $E V A$ e o $M V A$, porém a 
correlação seria melhor, quando da utilização do $R O A$ e $R O E$. O estudo encontrou uma relação mais forte entre a remuneração dos executivos e o EVA, contrariando Fatemi et al. (2003).

Lin et al. (2013) testaram empiricamente os determinantes da remuneração dos executivos. O intuito foi compreender o fenômeno "fat cat problem", ou seja, empresas com baixo desempenho que possuem CEOs com alta remuneração. Os autores utilizaram uma amostra composta por 903 empresas americanas no período de 2007 a 2010. As proxies utilizadas para o desempenho foram o ROA e o ROE. Os resultados apontaram que: i) empresas maiores pagam mais aos seus CEOs; ii) CEOs com idade mais avançada, possuem maior remuneração em dinheiro; iii) existe uma ausência geral de vínculo entre remuneração e desempenho.

Bussin e Modau (2015) investigaram a relação entre a remuneração do CEO e o desempenho das organizações na África do Sul no período de 2006 a 2012. Foram investigadas 21 empresas listadas na Bolsa de Valores de Joanesburgo. Os autores utilizaram como medidas o Market Capitalisation (MC), Earnings per Share (EPS), ROE, EVA e MVA. Os resultados indicam que os executivos se distanciaram visivelmente do foco em incentivos de curto prazo. O distanciamento ocorreu pelo afastamento dos elementos relacionados ao desempenho nos contratos de remuneração, resultando em uma desconexão entre remuneração e desempenho.

Raithatha e Komera (2016) tiveram como objetivo examinar a relação entre a remuneração dos executivos e o desempenho da empresa na Índia. Os autores utilizaram como medida de desempenho o $R O A, R O E$ (medidas baseadas na contabilidade), o $\mathrm{Q}$ de Tobin e Retorno anual das ações (medidas baseadas no mercado). Para controle, foram utilizados o tamanho, alavancagem e risco. As evidências sugerem que as empresas determinam a remuneração dos executivos com base nas medidas de desempenho contábil.

Smirnova e Zavertiaeva (2017) investigam se as empresas vinculam a remuneração do CEO a indicadores financeiros específicos e os efeitos do nível de desempenho empresarial a partir de dados contábeis. As métricas utilizadas para mensurar o desempenho foram o ROA e o índice de Sharpe (retorno ajustado ao risco). Os resultados evidenciam que as empresas vinculam o pagamento do CEO (em particular) o pagamento total e bônus a medidas baseadas na contabilidade. O índice de Sharpe, como uma medida de desempenho baseada no mercado, influencia todos os tipos de remuneração, exceto os benefícios.

No Brasil, os estudos sobre remuneração e desempenho ainda são controversos. Tradicionalmente, os autores utilizam como medida o ROA e o ROE (Krauter, 2013; Machado e Rogers, 2016; Cunha et al., 2016; Souza, Cardoso e Vieira, 2017; Lopes, Gasparetto, Schnorrenberger e Lunkes, 2018; Beuren et al., 2020). Além disso, apesar da controvérsia existente na literatura, espera-se que exista vínculo entre a remuneração dos CEOs e o desempenho empresarial, por meio da utilização de medidas de criação de valor. Diante do exposto, este estudo assume as seguintes hipóteses de pesquisa:

- $\mathbf{H}_{1}$ : Existe relação positiva e significativa entre a remuneração dos CEOs e o Economic Value Added (EVA).

- $\mathbf{H}_{2}$ : Existe relação positiva e significativa entre a remuneração dos CEOs e o Market Value Added $(M V A)$.

\section{Metodologia}

\subsection{Classificação da Pesquisa, Amostra e Coleta de Dados}

A pesquisa se caracteriza como descritiva, quantitativa e documental. A população foi composta pelas empresas brasileiras listadas na B3 e pertencentes ao índice IBRX 100, trata-se de um indicador de desempenho médio das cotações dos 100 ativos de maior negociabilidade e representatividade do mercado de ações brasileiro. Este indicador é formado por empresas heterogêneas, que pertencem a setores distintos e classificadas em diferentes segmentos de governança corporativa. Ressalta-se que não estão incluídos nesse universo BDRs e ativos de companhias em recuperação judicial ou extrajudicial, regime especial de administração temporária, intervenção ou que sejam negociados em qualquer outra situação especial de listagem (B3, 2021).

Com base na análise dos dados, foi necessária a exclusão de 25 empresas, sendo que vinte e três (23) pertenciam ao setor financeiro e duas (2) tiveram dados ausentes. O setor financeiro foi excluído a partir das considerações de Vilela (2013), para o autor, o MVA possui restrição de utilização no caso de bancos, destacando-se a inviabilidade da avaliação das unidades de negócio a preços de mercado e a volatilidade sistemática de mercado para o preço das ações.

Portanto, a amostra, não probabilística, foi composta por 75 empresas e 351 observações, formando um painel desbalanceado. A análise foi realizada no período de 2015 a 2019 (seis anos). A limitação amostral foi necessária devido ao esforço despendido para a coleta de dados. Embora a divulgação da remuneração dos executivos tenha melhorado no Brasil com a publicação da Instrução Normativa CVM no 480/09, os dados ainda não estão disponíveis em formato eletrônico. Logo, a maior parte 
das variáveis foi coletada manualmente. Ademais, as informações sobre remuneração estavam disponíveis até o exercício de 2019.

Ressalta-se que o espaço temporal utilizado nessa pesquisa contempla períodos de estabilidade e recessão econômica no Brasil. Os períodos marcados pela recessão foram os anos de 2015 e 2016. Para Jensen e Murphy (2010), em épocas de crise faz sentido um aumento na remuneração salarial dos executivos como forma de retenção. Por outro lado, Anderson et al., (2010) afirmam que os salários dos CEOs podem ser reduzidos em períodos de recessão econômica. Sendo assim, o trabalho buscou controlar os efeitos das variações econômicas sobre a remuneração.

Os dados de natureza secundária foram obtidos e/ou calculados da seguinte forma: (i) as informações para cálculo do EVA, MVA e tamanho da empresa foram extraídas a partir da base de dados do Economáticå; (ii) as informações para cálculo do Custo Médio Ponderado de Capital (CMPC) foram extraídas a partir da base do Economática® e dados disponibilizados por Damodaran (2019). O cálculo do CMPC seguiu as diretrizes propostas no estudo de Neto et al., (2008), considerando os seguintes itens: empréstimos e financiamento de curto prazo, empréstimos e financiamento de longo prazo, debêntures de curto prazo, debêntures de longo prazo, patrimônio líquido; despesas financeiras; Rf (média 10 anos tesouro americano); T-Bond 10 + Risco país; Beta - 60 meses; Market Risk Premium; (iii) as informações sobre a remuneração dos CEOs, as características observáveis dos CEOs e do conselho de administração, bem como as variáveis de governança, foram extraídas manualmente, a partir do Formulário de Referência (FR), disponível no site da B3; e (iv) o valor da variação do PIB foi extraído no site do IBGE.

\subsection{Especificação do Modelo Econométrico}

Os modelos usados foram operacionalizados por meio do pacote estatístico Stata®. A fim de verificar a relação entre a remuneração dos CEOs e a criação de valor em empresas brasileiras, optou-se pela utilização do modelo de regressão linear múltipla, estimado pelo Método dos Momentos Generalizado Sistêmico (GMM Sistêmico). Pesquisadores anteriores apontaram para o potencial problema de endogeneidade nos modelos de remuneração de executivos (Ozkan, 2011). Dessa forma, os modelos deste trabalho foram analisados pelo método GMM Sistêmico, que é uma metodologia mais apropriada para tratar problemas econométricos, principalmente a relação endógena entre as variáveis (Blundell \& Bond,1998). O GMM Sistêmico também foi estimado com dois estágios e com a correção de Windmeijer, para aumento da robustez.

A partir da revisão de literatura, procedeu-se com a estimação das equações (1) e (2) por meio de uma regressão de dados em painel.

$$
\begin{gathered}
R M_{i t}=\beta_{1} E V A_{i t-1}+\beta_{2} T_{A M}+\beta_{3} A G E_{i t}+\beta_{4} \Delta P I B_{i t}+\beta_{5} T_{A M M_{B O A R D} i t}+\beta_{6} T A M_{C F_{i t}}+u_{i t} \\
R M_{i t}=\beta_{1} M V A_{i t-1}+\beta_{2} T A M_{i t}+\beta_{3} A G E_{i t}+\beta_{4} \Delta P I B_{i t}+\beta_{5} T A M_{-} B O A R D_{i t}+ \\
\beta_{6} T A M_{-} C F_{i t}+u_{i t}
\end{gathered}
$$

Onde $i=1, \ldots, N$ representa as empresas da amostra e $t=1, \ldots, T$ representam os anos analisados (2015-2019); $\beta$ é o coeficiente angular estimado para cada variável independente; $u_{i t}=\alpha_{i}+\varepsilon_{i t}$ é o termo de erro composto em que $\alpha_{i}$ é o efeito individual não observado e $\varepsilon_{i t}$ é o termo de erro aleatório. As variáveis dos modelos são descritas no Quadro 1.

Embora o GMM Sistêmico também não suponha que as variáveis tenham distribuição normal e a presença de heterocedasticidade não inviabilize a sua aplicação, para que os resultados dos modelos estimados sejam robustos, alguns pressupostos precisam ser atendidos (Caixe, Matias e Oliveira, 2013).

Assim, a fim de validar o modelo e obter resultados consistentes, foram aplicados os seguintes testes: (i) teste de Raiz Unitária: a condição do GMM Sistêmico de que as primeiras diferenças das variáveis instrumentais não são correlacionadas com os efeitos fixos será satisfeita se o processo for estacionário (Blundell \& Bond, 1998), para isso, o teste utilizado foi o de Phillips-Perron (PP) cuja a hipótese nula é que todos os painéis contêm uma raiz unitária e a hipótese alternativa, é que pelo menos um painel é estacionário; (ii) teste de Autocorrelação de Arellano Bond: o teste é aplicado para verificar a autocorrelação no termo de erro idiossincrático, espera-se uma autocorrelação de primeira ordem negativa e significativa, mas de segunda ordem não significativa; (iii) teste Sargan/Hansen: para a validação do GMM, o pressuposto fundamental é que os instrumentos sejam exógenos, a fim de verificar tal pressuposição podem ser utilizados dois testes, o teste de Sargan e o teste de Hansen, sendo o teste de Hansen considerado superior; (iv) teste de Diferença de Hansen: testa a validade do subconjunto de instrumentos, a hipótese nula do teste assume que os subconjuntos de instrumentos são exógenos, quando não rejeitada, indica que as condições adicionais para o uso do GMM Sistêmico são válidas (Roodman, 2009).

Ressalta-se que apesar do GMM Sistêmico proporcionar estimativas robustas, mesmo os modelos apresentando diversos problemas econométricos, os modelos foram estimados também pelo Método de Mínimos Quadrados Ordinários (MQO) para dados agrupados (Pooled) a fim de verificar seus pressupostos, 
garantindo maior robustez aos resultados. Nesse sentido, foram aplicados os seguintes testes: (i) o fator de inflação da variância (Variance Inflation Fator - VIF), para detectar a presença de multicolinearidade dos regressores; (ii) teste de Breusch-Pagan para verificar a homocedasticidade do termo de erro; (iii) o teste RESET (regression specification error test) de Ramsey a fim de examinar a correta especificação do modelo; e (iv) o teste de Doornik-Hansen para averiguar a normalidade dos resíduos.

\subsection{Descrição das Variáveis}

A variável dependente do estudo é o valor total da remuneração dos CEOs (RM) que compreende a remuneração fixa e a remuneração variável. Utilizou-se o logaritmo da remuneração individual máxima da diretoria estatutária, disponível no item 13.11 do Formulário de Referência. Larcker e Tayan (2019) afirmam que, em média, nos Estados Unidos, o CEO ganha 1,8 vezes o salário do segundo maior executivo, e o segundo maior ganha 1,2 vezes a mais do que o terceiro. Dessa forma, infere-se que o valor da maior remuneração da diretoria executiva é a do Chief Executive Officer (CEO). A partir de 2009, com a publicação da Instrução Normativa CVM no 480/09, as empresas passaram a divulgar obrigatoriamente a remuneração mínima, remuneração média e remuneração máxima dos executivos. Figura 1.

A partir da literatura foram definidas as variáveis independentes do estudo, conforme descrito na

\begin{tabular}{|c|c|c|c|}
\hline Variável & Operacionalização & Sinal Esperado & Fonte \\
\hline \multicolumn{4}{|c|}{ Principais variáveis de interesse } \\
\hline $\begin{array}{l}\text { Economic Value } \\
\text { Added } \\
{\left[\mathrm{EVA}_{(\mathrm{t}-1)}\right]}\end{array}$ & $\begin{array}{c}\text { Lucro Operacional } \\
-(\text { Capital Investido* CMPC) } \\
C M P C=\left(\boldsymbol{W e}{ }^{*} \boldsymbol{K e}\right)+\left(\boldsymbol{W d}{ }^{*} \boldsymbol{K} \boldsymbol{d}\right) \\
\text { Variável defasada em um período }\end{array}$ & + & $\begin{array}{l}\text { Bussin e Modau (2015); Wet } \\
\text { (2012); Fatemi et al. (2003). }\end{array}$ \\
\hline $\begin{array}{l}\text { Market Value } \\
\text { Added } \\
{\left[\mathrm{MVA}_{(\mathrm{t}-1)]}\right.}\end{array}$ & $\begin{array}{l}\text { Valor de mercado das ações } \\
\text { - (Valor contábil do PL) } \\
\text { Variável defasada em um período }\end{array}$ & + & $\begin{array}{l}\text { Bussin e Modau (2015); Wet } \\
\text { (2012); Fatemi et al. (2003). }\end{array}$ \\
\hline \multicolumn{4}{|c|}{ Variáveis de controle } \\
\hline $\begin{array}{l}\text { Tamanho } \\
\text { (TAM) }\end{array}$ & Ln do ativo total da empresa & + & $\begin{array}{c}\text { Lin et al. (2013); Lin e Lin } \\
\text { (2014); Ozkan (2011); } \\
\text { Chalevas (2011); Cunha et al., } \\
\text { (2016) }\end{array}$ \\
\hline $\begin{array}{l}\text { Variação do PIB } \\
(\Delta \mathrm{PIB})\end{array}$ & $\begin{array}{l}\text { Variação do PIB de um período para o } \\
\text { outro, a fim de verificar oscilações nos } \\
\text { períodos da economia. }\end{array}$ & + & $\begin{array}{c}\text { Bussin e Modau (2015); } \\
\text { Kaplan (2012); Anderson et al. } \\
\text { (2010); Jensen e Murphy } \\
(2010) .\end{array}$ \\
\hline $\begin{array}{l}\text { Idade do CEO } \\
\text { (AGE) }\end{array}$ & $\begin{array}{l}\text { Anos de vida obtido pela data de } \\
\text { nascimento do CEO. }\end{array}$ & + & $\begin{array}{l}\text { Lin et al. (2013); Ozkan } \\
\text { (2011). }\end{array}$ \\
\hline $\begin{array}{l}\text { Tamanho do Board } \\
\text { (TAM_BOARD) }\end{array}$ & $\begin{array}{l}\text { Número de membros no conselho de } \\
\text { administração ao final de cada ano }\end{array}$ & + & $\begin{array}{l}\text { Ozkan (2011); Lin et al. } \\
\text { (2013); Cunha et al., (2016) }\end{array}$ \\
\hline $\begin{array}{l}\text { Tamanho do } \\
\text { Conselho Fiscal } \\
\text { (TAM_CF) }\end{array}$ & $\begin{array}{l}\text { Número de membros do conselho fiscal } \\
\text { ao final de cada ano }\end{array}$ & & \\
\hline
\end{tabular}

Figura 1 - Resumo das variáveis independentes

Fonte: Elaborado pelas autoras.

As variáveis independentes, utilizadas para medir a criação de valor foram o Economic Value Added (EVA) e o Market Value Added (MVA). Nos modelos principais deste estudo, tais medidas não foram utilizadas em um único modelo, tendo em vista destaques da literatura sobre a possibilidade de correlação entre elas (Wet, 2012), sendo usadas em conjunto nos testes de robustez. Além disso, foram ponderadas pelo ativo total e utilizadas de forma defasada, ou seja, considerou-se o período anterior. Quanto às variáveis de controle, tem-se: o tamanho da empresa medido pelo logaritmo natural do ativo, a variação do produto interno bruto (PIB) anual, a idade do CEO, o tamanho do conselho de administração (board) e o tamanho do conselho fiscal. Por fim, ressalta-se que nas análises de robustez foram incluídas as variáveis dummies: dualidade, gênero do CEO e do board, formação do board e auditoria por Big Four; além disso testadas a remuneração fixa e variável. 


\section{Análise dos Resultados}

\subsection{Análise Descritiva}

$\mathrm{Na}$ Tabela 1, encontram-se os dados descritivos das variáveis quantitativas utilizadas nos modelos de regressão. A variável remuneração dos CEOs (RM) apresentou baixa variabilidade, com um coeficiente de variação de $7,33 \%$. Em média, os executivos da amostra receberam um salário anual de $\mathrm{R} \$ 8,00$ milhões de reais, a média da remuneração logaritmizada foi de 15,89.

Tabela 1

Estatística descritiva das variáveis quantitativas

\begin{tabular}{cccccccc}
\hline & No Obs. & Mínimo & Máximo & Mediana & Média & $\begin{array}{c}\text { Desvio } \\
\text { Padrão }\end{array}$ & $\begin{array}{c}\text { Coeficiente de } \\
\text { Variação }\end{array}$ \\
\hline RM & 348 & 11,43 & 18,24 & 15,445 & 15,3504 & 1,1245 & $7,33 \%$ \\
EVA $_{(t-1)}$ & 250 & $-0,17$ & 0,15 & 0,02 & 0,0190 & 0,0441 & $232,80 \%$ \\
MVA $_{(t-1)}$ & 342 & $-0,64$ & 4,18 & 0,315 & 0,5864 & 0,8535 & $145,56 \%$ \\
TAM & 351 & 13,15 & 20,65 & 16,53 & 16,5947 & 1,2657 & $7,63 \%$ \\
AGE & 350 & 36 & 87 & 57 & 56,2857 & 9,4182 & $16,73 \%$ \\
TAM_BORD & 351 & 2 & 30 & 9 & 9,7208 & 4,2764 & $43,99 \%$ \\
TAM_CF & 351 & 0 & 10 & 3 & 3,3675 & 2,5364 & $75,32 \%$ \\
$\Delta$ PIB & 351 & $-3,55$ & 1,32 & 1,14 & $-0,540$ & 2,2795 & $-422,12 \%$ \\
\hline
\end{tabular}

Fonte: Elaborada pelas autoras.

Notas: RM: Remuneração total dos CEOs; EVA: Economic Value Added; MVA: Market Value Added; TAM: Tamanho; AGE: Idade do CEO; $\triangle \mathrm{PIB}$ : variação do PIB; TAM_BORD: tamanho do Board; TAM_CF: tamanho do conselho fiscal.

Ao analisar a remuneração dos CEOs por setor, na Tabela 2, a partir dos coeficientes de variação, nota-se que, no geral, não há grande variabilidade da remuneração dos CEOs nos setores analisados. $O$ setor que apresentou em média a maior remuneração foi o de comunicações $(16,50)$, porém na amostra analisada existiam apenas seis empresas pertencentes a esse setor. Por outro lado, o setor com remuneração média mais baixa foi o de utilidade pública $(14,48)$.

Tabela 2

Estatística descritiva da remuneração total dos CEOs (RM) por setor (logaritmizada)

\begin{tabular}{cccccccc}
\hline RM por setor & No Obs. & Mínimo & Máximo & Mediana & Média & $\begin{array}{c}\text { Desvio } \\
\text { Padrão }\end{array}$ & $\begin{array}{c}\text { Coeficiente } \\
\text { Variação }\end{array}$ \\
\hline Bens industriais & 38 & 12,71 & 16,94 & 15,74 & 15,28 & 1,1421 & $7,48 \%$ \\
Comunicações & 6 & 15,28 & 18,24 & 16,28 & 16,50 & 1,0661 & $6,46 \%$ \\
Consumo cíclico & 96 & 13,36 & 17,45 & 15,54 & 15,49 & 1,0186 & $6,57 \%$ \\
Consumo não cíclico & 33 & 13,95 & 17,72 & 16,13 & 16,01 & 0,9023 & $5,63 \%$ \\
Materiais básicos & 49 & 12,85 & 17,89 & 15,55 & 15,52 & 1,1503 & $7,41 \%$ \\
Petróleo, gás e & 18 & 14,51 & 17,12 & 15,43 & 15,48 & 0,7870 & $5,09 \%$ \\
biocombustíveis & 24 & 14,70 & 17,57 & 16,00 & 16,05 & 0,6529 & $4,07 \%$ \\
$\quad$ Saúde & 11 & 14,04 & 16,72 & 15,07 & 15,05 & 0,7886 & $5,24 \%$ \\
Tecnologia da informação & 73 & 11,43 & 16,52 & 14,44 & 14,48 & 1,0242 & $7,07 \%$ \\
Utilidade pública & 73 & & & & &
\end{tabular}

Fonte: Elaborada pelas autoras.

Por meio da análise das medidas de criação de valor mostradas na Tabela 1, apresentam-se as seguintes considerações: as variáveis EVA e MVA mostraram uma alta variabilidade nos dados, 0 coeficiente de variação é $232,80 \%$ para o EVA e de $145,56 \%$ para o $M V A$, sinalizando grande heterogeneidade. A partir dos valores mínimos e máximos, percebe-se a existência de criação e destruição de valor nas empresas estudadas. A mediana do EVA é 0,02 e a do $M V A, 0,32$, ou seja, mais da metade dos dados sinalizam para a criação de valor nas empresas.

Esses resultados se mostram mais promissores, quando comparados aos estudos de Wet (2012) em empresas sul-africanas, cujas médias desses indicadores foram negativas, no período de 2006 a 2010 , indicando a destruição de riqueza, em termos de uma medida interna $(E V A)$ e também, de uma medida externa (MVA). Ressalta-se, no entanto, que a amostra utilizada neste estudo é de empresas listadas na B3 e pertencentes ao índice IBRX 100.

Quanto ao tamanho (TAM) da empresa, dado pelo logaritmo natural do ativo total, identificou-se uma baixa variabilidade, com um coeficiente de variação de $7,63 \%$, sinalizando que as empresas analisadas possuem um tamanho uniforme, o que pode estar relacionado ao índice ao qual pertencem (IBRX 100). Ao analisar a idade dos CEOs, nota-se homogeneidade nos dados com um coeficiente de variação de $16,73 \%$. O CEO com maior idade possui 87 anos e o de menor idade, 36 anos. Já a idade média é de aproximadamente 56 anos. Esse resultado é semelhante ao encontrado por Ozkan (2011), sobre os CEOs do Reino Unido, cuja média de idade foi de 51 anos, indicando que como o CEO ocupa uma posição muito importante na empresa é de se esperar que seja uma pessoa com mais vivência. 
As variáveis que medem o tamanho do conselho de administração (TAM_BOARD) e do conselho fiscal (TAM_CF) apresentaram maior variabilidade $43,99 \%$ e $75,32 \%$, respectivamente. O conselho de administração revelou uma quantidade mínima de dois integrantes e o máximo de 30 , sendo que em mais da metade das observações existia mais de 9 integrantes nos conselhos. Já o conselho fiscal apresentou o mínimo de 0 , indicando que algumas empresas não possuem esse conselho. Ressalta-se que em mais da metade das observações haviam mais de três membros no conselho fiscal.

Por fim, a variação do PIB ( $\triangle \mathrm{PIB})$, que captou as oscilações no ambiente econômico brasileiro ano a ano, demonstrou uma grande variabilidade no período analisado com um coeficiente de variação de $422,12 \%$. Enfatiza-se que o Brasil passou por um período de recessão nos anos de 2015 e 2016, com variação no PIB de -3,55 e -3,28, respectivamente. Já, nos anos de 2017, 2018 e 2019, houve recuperação econômica, com variação do PIB positiva. Ao analisar a remuneração dos CEOs ao longo do período, considerando a mediana, observa-se que, nos períodos de recessão econômica (2015 e 2016), a remuneração dos CEOs foi menor, havendo um crescimento acentuado a partir de 2017.

\subsection{Análise Econométrica}

Considerando a relação endógena entre a variável dependente, representada pela remuneração dos CEOs (RM) e as variáveis independentes de criação de valor, assim como a estrutura longitudinal da pesquisa, para analisar a relação entre remuneração dos CEOs e a criação de valor em empresas brasileiras listadas que compõem o IBRX 100, utilizou-se o modelo de regressão de dados em painel estimado pelo GMM Sistêmico desenvolvido por Blundell e Bond (1998). No entanto, os modelos também foram estimados pelo método MQO (pooled) para verificar os seus pressupostos. Além disso, em todas as análises econométricas deste trabalho foi considerado o nível de significância de $5 \%$.

Com o intuito de testar as hipóteses propostas foram estimados dois modelos econométricos, considerando as variáveis de criação de valor EVA e MVA. O modelo foi validado conforme sugerido pela literatura, sendo seus resultados e testes das estimações descritos na Tabela 3.

Antes de estimar o GMM Sistêmico, os pressupostos do método MQO foram verificados. Nas estimações do modelo com o MVA não foi identificada multicolinearidade nas variáveis, com o VIF foi de 1,26; o teste de Breusch-Pagan demonstrou que os erros heterocedásticos, sendo necessário utilizar errospadrão robustos para heterocedasticidade; o teste RESET indicou a existência de variáveis omitidas; e o teste de Doornik-Hansen demonstrou a não normalidade dos resíduos. Todavia, esse pressuposto pode ser flexibilizado pelo número de observações e as proposições do teorema do limite central. Assim, para o modelo do MVA houve problema apenas de especificação. Em relação ao modelo do EVA, todos os pressupostos do método MQO foram atendidos. Quanto à capacidade de explicação dos modelos, nota-se que o modelo para o $M V A$ teve maior poder de explicação ( $R^{2}$ ajustado de $\left.11,83 \%\right)$, em relação ao modelo do $E V A$ ( $\mathrm{R}^{2}$ ajustado foi de $8,4 \%$ ) (Tabela 3 ).

Já a análise de diagnóstico, considerando o GMM Sistêmico, indicou, primeiramente pelo teste de raiz unitária, a adequabilidade do uso do modelo, ao mostrar a existência de painéis com séries estacionárias conforme o teste de Phillips-Perron $(P P)$ para todas as variáveis independentes, com exceção da variação do PIB. No entanto, salienta-se que essa condição do painel estacionário é suficiente, mas não necessária para o GMM Sistêmico (Blundell \& Bond, 1998; Barros et al., 2010). Ao verificar a autocorrelação do termo de erro, obteve-se para ambos os modelos autocorrelação de primeira ordem negativa e significativa e de segunda ordem não significativa, atendendo ao previsto no GMM Sistêmico.

Quanto à exogeneidade dos instrumentos, o teste de Hansen (mais robusto) foi não significativo em todos os modelos, conforme a hipótese nula do teste de que os instrumentos são válidos. Além disso, os testes de diferença de Hansen (não significativos) confirmaram que os subconjuntos de instrumentos são exógenos e que se pode utilizar o GMM Sistêmico (Tabela 3). Logo, os dois modelos foram validados para 0 GMM Sistêmico.

Após validação do GMM Sistêmico, procede-se com a análise e discussão dos resultados apresentados na Tabela 3. Primeiramente serão analisadas as variáveis explicativas, medidas para a criação de valor, EVA e MVA. Na sequência, serão analisadas as variáveis de controle.

Com base nos resultados obtidos com a estimação do modelo, considerando a amostra analisada, não foram encontradas evidências que permitissem rejeitar a primeira hipótese de pesquisa: $\mathbf{H}_{1}$ : Existe relação positiva e significativa entre a remuneração dos CEOs e o Economic Value Added (EVA). Uma vez que o EVA defasado foi estatisticamente significativo a $5 \%$, os resultados indicam que um aumento no EVA do período anterior influencia uma maior remuneração atual dos executivos, o que confirma os argumentos de Tortella e Brusco (2003) de que algumas empresas podem fornecer incentivos para a utilização do EVA no processo decisório, apoiando os estudos de Fatemi et al. (2003) e Wet (2012) para essa variável.

Considerando que alguns estudos encontraram uma correlação positiva e significativa entre o EVA e o MVA (Walbert, 1994), elaborou-se a segunda hipótese de pesquisa, a partir de uma medida de criação de valor externa, sendo: $\mathbf{H}_{2}$ : Existe relação positiva e significativa entre a remuneração dos $C E O s$ e o Market Value Added (MVA). 
Tabela 3

Resultados das estimações com a variável dependente Remuneração Total

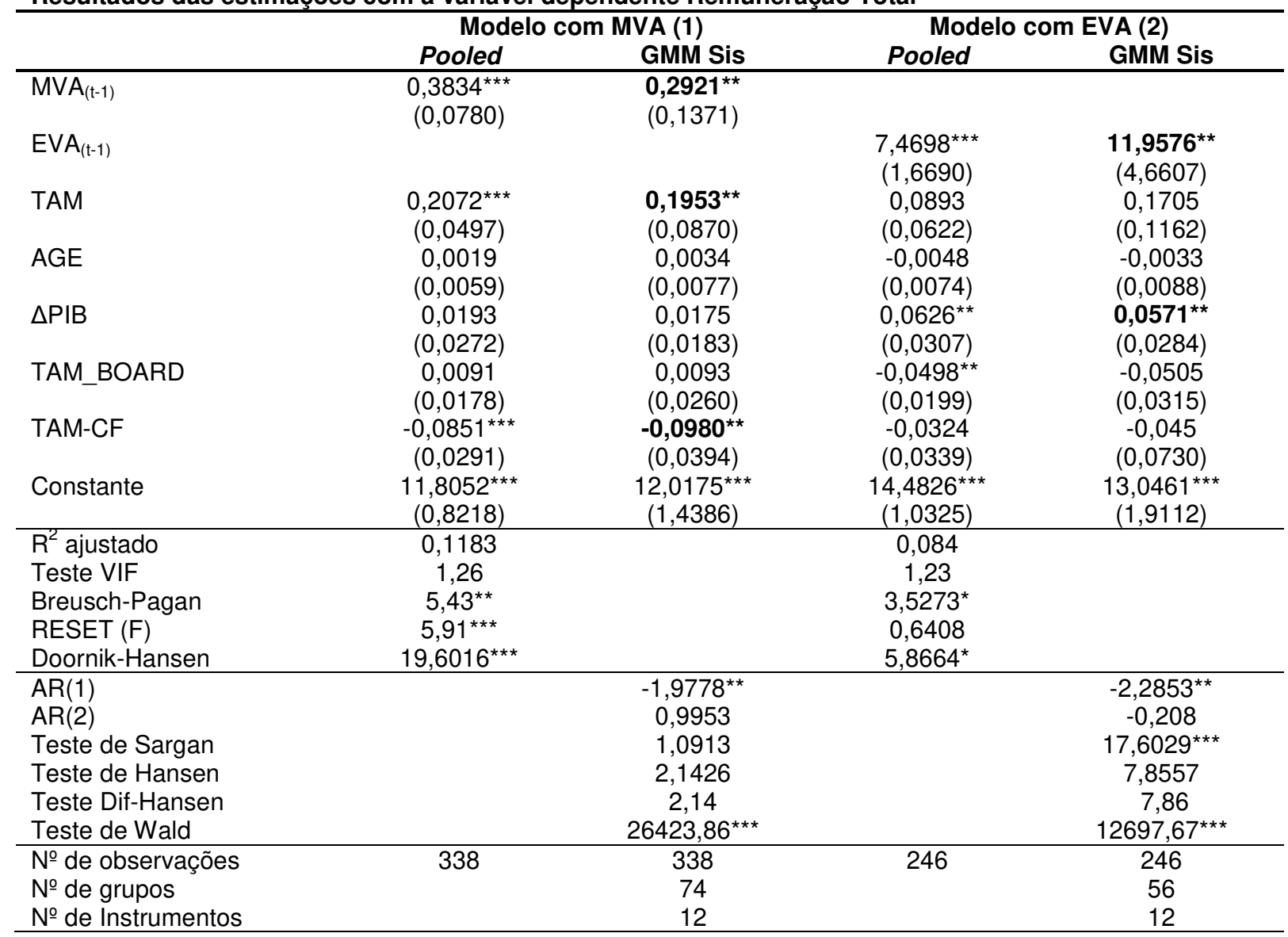

Fonte: Elaborada pelas autoras.

Notas: Foram instrumentalizadas as variáveis MVA e EVA. Assume-se que os demais regressores são exógenos. Os erros-padrão estão entre parênteses, nos testes é apresentado o valor da estatística e a significância estatística é indicada pelos símbolos: ${ }^{*} 10 \%$; ${ }^{* *} 5 \% ;{ }^{* * *} 1 \%$. RM: Remuneração dos CEOs; EVA: Economic Value Added; MVA: Market Value Added; TAM: tamanho; REC: Recessão Econômica; AGE: Idade do CEO; $\triangle \mathrm{PIB}$ : variação do PIB; TAM_BORD: tamanho do Board; TAM_CF: tamanho do conselho fiscal.

Os achados deste estudo também não permitiram rejeição da segunda hipótese de pesquisa, demonstrando que a remuneração dos CEOs é impactada de forma positiva e significativa pelo MVA defasado. Pode-se inferir que um aumento no MVA do período anterior provoca um aumento na remuneração total dos CEOs. Tal constatação, corroboram com os estudos de Fatemi et al. (2003) e Wet (2012) em empresas americanas e sul-africanas. Para os autores, o MVA é um determinante significativo da remuneração dos executivos, sendo esses, compensados por adições ao $M V A$, o que demonstra uma preocupação das empresas com a criação de valor no longo prazo.

Assim, ao utilizar proxies de criação de valor (EVA e MVA) defasadas para capturar o desempenho passado da organização, foi possível identificar que a remuneração dos CEOs para a amostra estudada está vinculada a geração de riqueza passada da organização. Tal fato, supõe uma tentativa das empresas analisadas em mitigar possíveis problemas de agência com uma política de remuneração que se alinhe a criação de valor. Demonstrando que ambas as medidas de criação de valor, uma baseada na contabilidade (EVA) e a outra nas informações de mercado (MVA), mostraram um vínculo com a remuneração.

Esse achado vai ao encontro da constatação de Kruger e Petri (2014), a qual sugere a importância da utilização do EVA e do MVA para medir o retorno dos investimentos e a geração de valores aos acionistas, servindo como indicativos preditivos para analisar o desempenho empresarial, considerando 0 custo de oportunidade do capital (EVA) e a percepção do mercado frente à gestão do capital (MVA).

Adicionalmente, esta pesquisa testou variáveis de controle que podem se relacionar com a remuneração dos CEOs, quais sejam: tamanho, idade do CEO, variação do $\mathrm{PIB}$, tamanho do conselho de administração e tamanho do conselho fiscal.

A variável tamanho (TAM) foi significativa, a $5 \%$, e positiva no modelo do $M V A$, sendo possível inferir que o tamanho da empresa está positivamente associado à remuneração dos CEOs. Os achados corroboram com os estudos de Ozkan (2011); Lin et al. (2013); Lin e Lin (2014) e Cunha et al., (2016). Os autores afirmam que o tamanho da empresa possui uma relação positiva com a remuneração de executivos, dado que empresas maiores remuneram melhor e possuem maior capacidade de contratar executivos qualificados (Chavelas, 2011). 
A variação do PIB buscou captar as oscilações econômicas durante os anos analisados. Essa variável foi positiva e significativa a $5 \%$ para o modelo $M V A$, sugerindo que uma variação positiva no PIB está associada a um aumento na remuneração dos CEOs. Os achados ressaltam os efeitos da situação econômica do país nos salários dos CEOs, em conformidade com as descobertas que destacam a influência do ambiente externo na remuneração dos CEOs, bem como a sensibilidade da remuneraçãodesempenho, que tende a flutuar com as tendências macroeconômicas (Bussin, 2015).

Por fim, a variável de tamanho do conselho fiscal também foi significativa a $5 \%$ e negativa no modelo do MVA. Essa variável capta um componente importante da governança corporativa e sugere que um aumento no número de integrantes do conselho fiscal, ou mesmo a presença desse conselho, está associado a uma menor remuneração dos CEOs. Esse resultado vai de encontro da característica desse órgão no Brasil, pois se trata de um mecanismo de fiscalização independente dos administradores, para reporte aos sócios, cujo objetivo é preservar o valor da organização (IBGC, 2015). Assim, o resultado sugere que o conselho fiscal seja um elemento capaz de inibir a remuneração excessiva dos CEOs. Não foram significativas, em ambos os modelos, as variáveis de idade do CEO e tamanho do conselho de administração.

\subsection{Testes de robustez}

A fim de obter maior robustez aos resultados, realizou-se inferências com a inclusão de variáveis dummies para controle, incluindo em um único modelo o EVA e o $M V A$, e testou como variáveis dependentes a remuneração fixa e variável do CEO, de forma separada. As variáveis dummies utilizadas nos testes de robustez são apresentadas na Figura 2.

\begin{tabular}{|c|c|c|c|}
\hline Variável & Operacionalização & $\begin{array}{c}\text { Sinal } \\
\text { Esperado }\end{array}$ & Fonte \\
\hline \multicolumn{4}{|c|}{ Variáveis de dummies de controle } \\
\hline $\begin{array}{l}\text { Dualidade de Função } \\
\text { (DUAL) }\end{array}$ & $\begin{array}{c}\text { Assume valor igual a 1: quando há dualidade de } \\
\text { funções } \\
\text { Assume valor 0: caso contrário }\end{array}$ & + & $\begin{array}{c}\text { Chalevas (2011); Bethlem } \\
\text { (2012); Bugeja et al. } \\
\text { (2012); Cunha et al., } \\
\text { (2016), } \\
\end{array}$ \\
\hline $\begin{array}{l}\text { Gênero do CEO } \\
\text { (GEN_CEO) }\end{array}$ & $\begin{array}{l}\text { Assume valor igual a 1: Quando o CEO é do sexo } \\
\text { masculino. } \\
\text { Assume valor 0: caso contrário }\end{array}$ & + & $\begin{array}{l}\text { Bugeja et al. (2012); Vieito } \\
\text { e Khan (2012) }\end{array}$ \\
\hline $\begin{array}{l}\text { Auditoria por Big Four } \\
\text { (BIG4) }\end{array}$ & $\begin{array}{c}\text { Assume valor igual a 1: Quando a empresa é } \\
\text { auditada por uma Big Four } \\
\text { Assume valor 0: caso contrário }\end{array}$ & - & (Lopes et al., 2017) \\
\hline $\begin{array}{c}\text { Gênero do presidente } \\
\text { do Board } \\
\text { (GEN_BOARD) }\end{array}$ & $\begin{array}{c}\text { Assume valor igual a 1: Quando o presidente do } \\
\text { conselho de administração é do sexo masculino. } \\
\text { Assume valor 0: caso contrário }\end{array}$ & & \\
\hline $\begin{array}{l}\text { Formação do Board } \\
\text { (FORM_BOARD) }\end{array}$ & $\begin{array}{l}\text { Assume valor igual a 1: Quando a formação do } \\
\text { presidente do conselho de administração é } \\
\text { contador, ou economista ou administrador } \\
\text { Assume valor 0: caso contrário }\end{array}$ & & \\
\hline
\end{tabular}

Figura 2 - Resumo das variáveis qualitativas (dummies) usadas na análise de robustez

Fonte: Elaborado pelas autoras.

$\mathrm{Na}$ Tabela 4 são apresentadas as estatísticas descritivas das variáveis qualitativas (classificadas como 0 e 1) usadas nas análises de robustez. A variável DUAL (dualidade de funções), que assumiu valor igual a 1 quando o CEO acumula funções e 0 caso contrário, indicou que em $97,06 \%$ dos casos os CEOs das empresas analisadas se dedicavam exclusivamente à sua função, o que contribui para reduzir a influência nas decisões sobre remuneração. Tal resultado vai ao encontro dos achados de Martins e Júnior (2020), os quais apontam que na maioria das empresas estudadas os CEOs se dedicavam a uma única função.

Quanto ao gênero do CEO e do presidente do conselho de administração a amostra foi majoritariamente composta por membros do sexo masculino, com $96,58 \%$ e $97,65 \%$ respectivamente. Além disso, cerca de 92,59\% das empresas da amostra foram auditadas por uma Big Four, sendo elas: Deloitte, Ernst \& Young (EY), KPMG e PriceWaterhouseCoopers. No que se refere à formação do presidente do conselho de administração, teve-se que $41,94 \%$ dos presidentes possuem titulação em administração ou ciências contábeis ou economia.

Ao incluir as variáveis dummies nos modelos de remuneração, bem como trabalhar em conjunto com o EVA e o MVA, obteve-se mais três modelos de regressão (Tabela 5). Ao verificar os pressupostos de MQO, encontrou-se: o modelo com MVA (3) teve poder explicação de $15,36 \%$, porém continuou com problemas de especificação na forma funcional e de normalidade dos resíduos; o modelo com EVA (4) é capaz de explicar $15,08 \%$ da remuneração e não apresentou nenhum problema nos pressupostos; e 0 
modelo com EVA e MVA explicou cerca de $18,74 \%$ da variável dependente e não apresentou normalidade dos resíduos.

Tabela 4

Estatísticas descritivas das variáveis qualitativas usadas na análise de robustez

\begin{tabular}{cccccc} 
DUMMY & DUAL & GEN_CEO & GEN_BOARD & \multicolumn{1}{c}{ BIG4 } & FORM_BOARD \\
\hline 0 & $97,06 \%$ & $3,42 \%$ & $2,35 \%$ & $7,41 \%$ & $58,06 \%$ \\
1 & $2,94 \%$ & $96,58 \%$ & $97,65 \%$ & $92,59 \%$ & $41,94 \%$ \\
TOTAL & $100,00 \%$ & $100,00 \%$ & $100,00 \%$ & $100,00 \%$ & $100,00 \%$ \\
\hline
\end{tabular}

Fonte: Elaborada pelas autoras.

Notas: DUAL: Dualidade de Função; GEN_CEO: gênero do CEO; GEN_BOARD: gênero do presidente do conselho de administração; BIG4: auditoria por uma Big Four; FORM_BOARD: formação do conselho de administração.

Já os pressupostos necessários para a validação das estimações por GMM sistêmico, foram todos validados, sendo utilizadas as estimações desse método para as análises. O detalhe nas estimações de robustez fica para o aumento no número de variáveis, que traz como consequência a redução dos graus de liberdade dos modelos.

Tabela 5

Resultados de robustez das estimações com variável dependente de remuneração total (RM)

\begin{tabular}{|c|c|c|c|c|c|c|}
\hline & \multicolumn{2}{|c|}{ Modelo com MVA (3) } & \multicolumn{2}{|c|}{ Modelo com EVA (4) } & \multicolumn{2}{|c|}{ Modelo com EVA e MVA (5) } \\
\hline & Pooled & GMM Sis & Pooled & GMM Sis & Pooled & GMM Sis \\
\hline $\mathrm{MVA}_{(t-1)}$ & $\begin{array}{c}0,3515^{\star \star \star} \\
(0,0745)\end{array}$ & 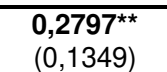 & & & $\begin{array}{c}0,2971^{* \star *} \\
(0,0885)\end{array}$ & $\begin{array}{c}0,1866 \\
(0,2172)\end{array}$ \\
\hline $\mathrm{EVA}_{(\mathrm{t}-1)}$ & & & $\begin{array}{c}7,5833^{\star * \star} \\
(1,6495)\end{array}$ & $\begin{array}{l}\mathbf{6 , 8 9 1 4} 4^{\star \star} \\
(2,7032)\end{array}$ & $\begin{array}{c}5,7039^{\star * *} \\
(1,7080)\end{array}$ & $\begin{array}{l}5,8006^{\star \star *} \\
(2,9444)\end{array}$ \\
\hline TAM & $\begin{array}{c}0,1900^{* * *} \\
(0,0534)\end{array}$ & $\begin{array}{l}\mathbf{0 , 1 8 5 6 * *} \\
(0,0904)\end{array}$ & $\begin{array}{c}0,075 \\
(0,0613)\end{array}$ & $\begin{array}{c}0,1134 \\
(0,0863)\end{array}$ & $\begin{array}{c}0,1155^{\star} \\
(0,0611)\end{array}$ & $\begin{array}{c}0,1282 \\
(0,1090)\end{array}$ \\
\hline AGE & $\begin{array}{c}-0,0036 \\
(0,0065)\end{array}$ & $\begin{array}{c}-0,0006 \\
(0,0086)\end{array}$ & $\begin{array}{c}-0,0102 \\
(0,0073)\end{array}$ & $\begin{array}{l}-0,0035 \\
(0,0084)\end{array}$ & $\begin{array}{l}-0,0102 \\
(0,0072)\end{array}$ & $\begin{array}{l}-0,0036 \\
(0,0102)\end{array}$ \\
\hline$\triangle \mathrm{PIB}$ & $\begin{array}{c}0,0258 \\
(0,0266)\end{array}$ & $\begin{array}{c}0,0188 \\
(0,0199)\end{array}$ & $\begin{array}{l}0,0614^{\star *} \\
(0,0302)\end{array}$ & $\begin{array}{c}0,0488^{* * *} \\
(0,0187)\end{array}$ & $\begin{array}{c}0,0347 \\
(0,0306)\end{array}$ & $\begin{array}{c}0,0364 \\
(0,0378)\end{array}$ \\
\hline TAM_BOARD & $\begin{array}{c}0,0065 \\
(0,0166)\end{array}$ & $\begin{array}{c}0,009 \\
(0,0260)\end{array}$ & $\begin{array}{c}-0,0457^{* *} \\
(0,0197)\end{array}$ & $\begin{array}{c}-\mathbf{0}, 0382^{\star \star} \\
(0,0193)\end{array}$ & $\begin{array}{c}-0,0398^{\star *} \\
(0,0194)\end{array}$ & $\begin{array}{l}-0,0291 \\
(0,0214)\end{array}$ \\
\hline TAM_CF & $\begin{array}{c}-0,0622^{* *} \\
(0,0282)\end{array}$ & $\begin{array}{c}-0,0956^{\star \star} \\
(0,0391)\end{array}$ & $\begin{array}{c}-0,0105 \\
(0,0341)\end{array}$ & $\begin{array}{c}-0,0566 \\
(0,0437)\end{array}$ & $\begin{array}{c}-0,006 \\
(0,0333)\end{array}$ & $\begin{array}{c}-0,059 \\
(0,0572)\end{array}$ \\
\hline DUAL & $\begin{array}{c}0,1401 \\
(0,3531)\end{array}$ & $\begin{array}{c}0,339 \\
(0,3142)\end{array}$ & $\begin{array}{c}1,3229^{* * *} \\
(0,4871)\end{array}$ & $\begin{array}{c}0,5445 \\
(0,3342)\end{array}$ & $\begin{array}{c}1,3272^{* * *} \\
(0,4765)\end{array}$ & $\begin{array}{c}0,4704 \\
(0,5032)\end{array}$ \\
\hline BIG4 & $\begin{array}{c}0,0293 \\
(0,2223)\end{array}$ & $\begin{array}{c}0,0211 \\
(0,2137)\end{array}$ & $\begin{array}{c}-0,1587 \\
(0,2529)\end{array}$ & $\begin{array}{c}-0,126 \\
(0,2752)\end{array}$ & $\begin{array}{l}-0,2918 \\
(0,2506)\end{array}$ & $\begin{array}{c}-0,0098 \\
(0,3819)\end{array}$ \\
\hline FORM_BOARD & $\begin{array}{c}0,3846^{\star * *} \\
(0,1181)\end{array}$ & $\begin{array}{c}0,1786 \\
(0,1466)\end{array}$ & $\begin{array}{c}0,2743^{*} \\
(0,1451)\end{array}$ & $\begin{array}{c}0,1498 \\
(0,1696)\end{array}$ & $\begin{array}{c}0,2754^{*} \\
(0,1419)\end{array}$ & $\begin{array}{c}0,1536 \\
(0,1915)\end{array}$ \\
\hline GEN_CEO & $\begin{array}{c}1,1814^{\star * *} \\
(0,4392)\end{array}$ & $\begin{array}{c}\mathbf{0}^{\prime} \mathbf{7 7 6 7} 7^{\star \star \star} \\
(0,2151)\end{array}$ & $\begin{array}{c}1,3353^{* * *} \\
(0,4921)\end{array}$ & $\begin{array}{c}\mathbf{0 , 7 3 6 2}^{\star \star \star} \\
(0,1844)\end{array}$ & $\begin{array}{l}1,2096^{\star *} \\
(0,4829)\end{array}$ & $\begin{array}{c}\mathbf{0 , 6 7 4 1} \mathbf{1}^{\star \star \star} \\
(0,2379)\end{array}$ \\
\hline GEN_BOARD & $\begin{array}{c}-0,2353 \\
(0,3802)\end{array}$ & $\begin{array}{c}-0,1921 \\
(0,1426)\end{array}$ & $\begin{array}{c}-0,7791 \\
(0,5369)\end{array}$ & $\begin{array}{c}-0,4662^{\star *} \\
(0,2176)\end{array}$ & $\begin{array}{c}-0,7072 \\
(0,5257)\end{array}$ & $\begin{array}{c}-0,4660^{\star \star} \\
(0,1876)\end{array}$ \\
\hline Constante & $\begin{array}{c}11,2451^{\star * *} \\
(1,0388)\end{array}$ & $\begin{array}{c}11,7295^{\star * *} \\
(1,6277) \\
\end{array}$ & $\begin{array}{c}14,3670^{* * *} \\
(1,2996) \\
\end{array}$ & $\begin{array}{c}13,8180^{* * *} \\
(1,6790)\end{array}$ & $\begin{array}{c}13,6417^{\star \star \star} \\
(1,2896)\end{array}$ & $\begin{array}{c}13,2689^{* * *} \\
(2,0578)\end{array}$ \\
\hline $\begin{array}{l}\mathrm{R}^{2} \text { ajustado } \\
\text { Teste VIF } \\
\text { Breusch-Pagan } \\
\text { RESET (F) } \\
\text { Doornik-Hansen }\end{array}$ & $\begin{array}{c}0,1536 \\
1,2 \\
0,0552 \\
2,6923^{\star *} \\
11,3694^{\star \star \star}\end{array}$ & & $\begin{array}{c}0,1508 \\
1,17 \\
2,511 \\
1,784 \\
2,2553\end{array}$ & & $\begin{array}{c}0,1874 \\
1,21 \\
0,8501 \\
1,8573 \\
6,2456^{* *}\end{array}$ & \\
\hline $\mathrm{AR}(1)$ & & $-2.0206^{\star *}$ & & $-2,1241^{* *}$ & & $-1,9832^{\star *}$ \\
\hline$A R(2)$ & & 1,1127 & & 0,2336 & & 0,4656 \\
\hline Teste de Sargan & & 2,0834 & & 17,7831 & & 58,2546 \\
\hline Teste de Hansen & & 3,3179 & & 6,7728 & & 26,5973 \\
\hline Teste Dif-Hansen & & 0,71 & & 4,18 & & 10,09 \\
\hline Teste de Wald & & $71015,31^{\star \star \star}$ & & $32172,47^{\star \star \star}$ & & $81763,46^{\star \star \star}$ \\
\hline № de observações & 329 & 329 & 240 & 240 & 240 & 240 \\
\hline № de grupos & & 72 & & 55 & & 55 \\
\hline № de Instrumentos & & 17 & & 25 & & 39 \\
\hline
\end{tabular}

Fonte: Elaborada pelas autoras.

Notas: Foram instrumentalizadas as variáveis MVA e EVA. Assume-se que os demais regressores são exógenos. Os erros-padrão estão entre parênteses, nos testes é apresentado o valor da estatística e a significância estatística é indicada pelos símbolos: * $10 \%$; **5\%; *** $1 \%$. RM: Remuneração dos CEOs; EVA: Economic Value Added; MVA: Market Value Added; TAM: tamanho; REC: Recessão Econômica; AGE: Idade do CEO; $\triangle \mathrm{PIB}$ : variação do PIB; TAM_BORD: tamanho do Board; TAM_CF: tamanho do conselho fiscal; DUAL: Dualidade de Função; GEN_CEO: gênero do CEO; GEN_BOARD: gênero do presidente do conselho de administração; BIG4: auditoria por uma Big Four, FORM_BOARD: formação do conselho de administração.

Após a inclusão das dummies, o MVA defasado continuou positivo e significativo no modelo 3 , assim como o EVA defasado no modelo 4 e 5, confirmando os resultados anteriores (Tabela 3). A particularidade ficou com a não significância do MVA ao ser incluído em conjunto com o EVA, que pode ser 
consequência do aumento da colinearidade no modelo. Ademais, ressalta-se que a proxy de criação de valor EVA apresentou resultados mais consistentes nesta amostra, confirmando o efeito positivo do EVA na remuneração total dos CEOs.

Quanto as variáveis de controle, as estimativas obtidas na Tabela 5 confirmaram os efeitos do tamanho da empresa, tamanho do conselho fiscal e variação do PIB na remuneração total dos CEOs. Além disso, identificou-se um efeito significativo e negativo do tamanho do conselho de administração na remuneração (modelo 4), sugerindo que um aumento no tamanho do conselho resulta em uma menor remuneração para os CEOs. Ressalta-se que o conselho de administração é um importante instrumento de governança, auxiliando no alinhamento de interesses dos acionistas. Esse resultado para o tamanho do conselho de administração vai contra os achados de Ozkan (2011), Lin et al. (2013) e Cunha et al., (2016), que sugerem que um conselho maior pode ser menos eficaz no monitoramento da remuneração dos CEOs.

No que se refere às dummies que foram incluídas, algumas características observáveis dos CEOs e dos conselhos de administração se tornaram significativas. Primeiramente, destaca-se que o gênero do CEO se revelou significativo e positivo nos três modelos, demonstrado que o fato do CEO pertencer ao gênero masculino, proporciona uma maior remuneração, em comparação com CEOs do gênero feminino. $O$ resultado corrobora com o trabalho de Vieito e Khan (2012), cujos achados indicaram que executivos do gênero masculino, em média, recebem mais do que os executivos do gênero feminino. Logo, os resultados são congruentes com a literatura, indicando que ainda existe uma lacuna sobre o efeito do gênero na remuneração de executivos.

Outra variável dummy também significativa foi o gênero do presidente do conselho de administração (modelos 4 e 5). O resultado indica que quando o presidente do conselho de administração é do gênero masculino existe uma tendência da remuneração do CEO ser menor. Já as demais variáveis incluídas no modelo não foram estatisticamente significativas.

Adicionalmente, foram testadas em separado como variáveis dependentes, a remuneração fixa e remuneração variável dos CEOs nos modelos com EVA e MVA. Os resultados a partir dessas estimações não são foram apresentados, visto que, não foram estatisticamente significativos, não sendo possível fazer inferências nesta amostra de dados.

\section{Considerações Finais}

O estudo teve como o objetivo analisar a relação entre a remuneração dos CEOs e a criação de valor em empresas brasileiras listadas no IBRX 100. Ao verificar o efeito da criação de valor na remuneração dos CEOs, obtiveram-se resultados congruentes nas duas medidas de valor utilizadas: EVA e MVA.

Assim, a primeira hipótese do modelo não foi rejeitada, ou seja, existe uma relação significativa e positiva entre a remuneração dos CEOs e o EVA, sugerindo que o EVA do período anterior impacta na decisão de aumentar ou diminuir a remuneração do CEO. O EVA é uma medida obtida a partir de dados contábeis, que busca captar o lucro econômico da empresa, demonstrando na amostra estudada ser uma medida de desempenho relevante para a remuneração dos CEOs. Na mesma perspectiva, a segunda hipótese do modelo não foi rejeitada, ou seja, houve uma relação positiva e significativa entre o MVA e a remuneração dos CEOs. Ressalta-se que o MVA é uma medida que reflete a visão do mercado e incorpora expectativas futuras. Portanto, os achados desta pesquisa podem indicar um alinhamento entre a política de remuneração das empresas analisadas e a criação de valor das organizações, amenizando os conflitos de interesse entre agente e principal.

Conclui-se que as empresas estudadas podem estar relacionando a remuneração dos executivos a medidas de criação de valor, bem como sendo influenciadas por características contábeis (do EVA) que capturam o desempenho histórico e por questões do mercado (com o MVA) que se relacionam com o desempenho futuro. É importante que as empresas alinhem a estratégia empresarial à política de remuneração de executivos, o que contribuirá para a minimização de conflitos de interesse e para a geração de riqueza.

Além disso, os achados das variáveis de controle também chamam a atenção. Enfatizando-se os mecanismos de governança, conselho fiscal e conselho de administração, que afetaram negativamente a remuneração dos CEOs. Bem como a questão da desigualdade de gênero na remuneração dos executivos brasileiros e na ocupação de cargos de destaque, dado que a amostra estudada apresentou uma baixa proporção de mulheres ocupando cargos executivos e sugeriu que CEOs do gênero masculino possuem uma remuneração superior.

No que se refere às contribuições do trabalho, na prática, o EVA e o MVA podem surgir como métricas relevantes para auxiliar as instituições a desenharem os pacotes de remuneração de executivos de forma equilibrada e sustentável. Teoricamente, o estudo contribuiu para as discussões sobre o alinhamento entre o desempenho das organizações e a remuneração de seus executivos, considerando o contexto de um mercado em desenvolvimento como o brasileiro e testando variáveis que consideram os riscos do negócio, ou seja, medidas mais efetivas para medir a criação de valor. 
Este trabalho apresenta como limitação, a análise somente de empresas listadas pertencentes ao Índice IBRX 100, e em um período específico do tempo, dessa forma, os resultados não podem ser generalizados. Para pesquisas futuras, acredita-se que alguns pontos possam ser explorados: i) introduzir medidas tradicionais de desempenho, dentro da mesma amostra; ii) aprofundar a discussão sobre o impacto negativo da dualidade de funções na remuneração dos CEOs; iii) ampliar a discussão sobre a desigualdade de gênero na remuneração de cargos executivos.

\section{Referências}

Anderson, S., Collins, C., Pizzigati, S., \& Shih, K. (2010). CEO pay and the great recession. Annual Executive Compensantion Survey. Recuperado de: https://ips-dc.org/executive excess 2010/

Bebchuck, L. A., \& Spamann, H. (2009). Regulating bankers' pay. Georgetown Law Journal, Vol. 98, No. 2, pp. 247-287, 2010, Harvard Law and Economics Discussion Paper No. 641. Available at SSRN: https://ssrn.com/abstract=1410072

Berle, A. A., Jr. \& Means, G. C. (1932). The modern corporation and privaty property. New York: MacMillan.

Bethlem, A. S. (2012). O presidente e o comando da empresa. Rio Janeiro: UFRJ/COPPEAD.

Beuren, I. M., Pamplona, E., \& Leite, M. (2020). Remuneração dos Executivos e Desempenho em Empresas Brasileiras Familiares e Não Familiares. Revista de Administração Contemporânea, 24(6), 514-531. https://doi.org/10.1590/1982-7849rac2020190191

Blundell, R., \& Bond, S. (1998). Initial conditions and moment restrictions in dynamic panel data models. Journal of econometrics, 87(1), 115-143. https://doi.org/10.1016/S0304-4076(98)00009-8

Brigham, E. F., \& Gapenski, L. C. (1994). Financial management: theory and practice (No. 658.159 B855 1994). Dryden Press.

Bugeja, M., Matolcsy, Z. P., \& Spiropoulos, H. (2012). Is there a gender gap in CEO compensation? Journal of Corporate Finance, 18(4), 849-859. https://doi.org/10.1016/j.jcorpfin.2012.06.008

Bussin, M. (2015). Ceo pay-performance sensitivity in the South African context. South African Journal of Economic and Management Sciences, 18(2), 232-244. https://doi.org/10.17159/2222-3436/2015/v18n2a7

Bussin, M., \& Modau, M. F. (2015). The relationship between chief executive officer remuneration and financial performance in South Africa between 2006 and 2012. SA Journal of Human Resource Management, 13(1), 1-18. https://doi.org/10.4102/sajhrm.v13i1.668

Caixe, D. F., Matias, A. B., \& Oliveira, S. V. W. B. D. (2013). Free float e valor de mercado corporativo: Um estudo do período de 2001 a 2010. Organizações \& Sociedade, 20(67), 733-751.

https://doi.org/10.1590/S1984-92302013000400008

Camargos, M. A. (2008). Fusões e aquisições de empresas brasileiras: criação de valor, retorno, sinergias e risco. 2008. Tese de Doutorado, Universidade Federal de Minas Gerais.

Chalevas, C. G. (2011). The effect of the mandatory adoption of corporate governance mechanisms on executive compensation. The International Journal of Accounting, 46(2), 138-174.

https://doi.org/10.1016/i.intacc.2011.04.004

Chhaochharia, V., \& Grinstein, Y. (2009). CEO compensation and board structure. The Journal of Finance, 64(1), 231-261. https://doi.org/10.1111/j.1540-6261.2008.01433.x

Colvin, G. (2008). AmEx gets CEO pay right', Fortune, 21: 12-13. Recuperado em: 16 de maio de 2019, de: https://archive.fortune.com/magazines/fortune/fortune archive/2008/01/21/102659595/index.htm?postversio $\underline{\mathrm{n}=2008010805}$

Comissão de Valores Mobiliários. (2009). Instrução CVM 480. Recuperado em 20 de outubro, 2019, de http://conteudo.cvm.gov.br/legislacao/instrucoes/inst480.html 
Cunha, P., Vogt, M., \& Degenhart, L. (2016). Governança corporativa e remuneração dos diretores executivos das empresas Brasileiras. Enfoque: Reflexão Contábil, 35(2), 1-16. https://doi.org/10.4025/enfoque.v35i2.30924

Damodaran, A. (2000), Corporate Finance: Theory and Practice, John Wiley \& Sons, Inc.

Damodaran, A. (2019). Updated Data. Recuperado de: http://www.stern.nyu.edu/ adamodar/

Ehrbar, A. (1998). EVA: the real key to creating wealth. New York: John Wiley \& Sons.

Fatemi, A., Desai, A. S., \& Katz, J. P. (2003). Wealth creation and managerial pay: MVA and EVA as determinants of executive compensation. Global Finance Journal, 14(2), 159-179.

https://doi.org/10.1016/S1044-0283(03)00010-3

Finkelstein, S., \& Hambrick, D. C. (1988). Chief executive compensation: A synthesis and reconciliation. Strategic Management Journal, 9(6), 543-558. https://doi.org/10.1002/smj.4250090603

Firth, M., Fung, P. M., \& Rui, O. M. (2006). Firm performance, governance structure, and top management turnover in a transitional economy. Journal of Management Studies, 43(6), 1289-1330.

https://doi.org/10.1111/j.1467-6486.2006.00621.x

Frydman, C. \& Jenter, D. (2010) CEO Compensation, Annual Review of Financial Economics. Annual Reviews, 2, 75-102. https://doi.org/10.1146/annurev-financial-120209-133958

Guthrie, K., Sokolowsky, J., \& Wan, K. M. (2012). CEO compensation and board structure revisited. The Journal of Finance, 67(3), 1149-1168. https://doi.org/10.1111/j.1540-6261.2012.01744.x

Instituto Brasileiro de Governança Corporativa. (2015). Código das Melhores Práticas de Governança Corporativa. 5. Ed. São Paulo, SP: IBGC.

https://conhecimento.ibgc.org.br/Paginas/Publicacao.aspx?Publd=21138

Instituto Brasileiro de Governança Corporativa (2018). Remuneração dos administradores. 6. Ed. São Paulo, SP: IBGC, 2018. (Série: IBGC Pesquisa).

Jensen, M. C., \& Murphy, K. J. (2010). CEO incentives-It's not how much you pay, but how. Journal of Applied Corporate Finance, 22(1), 64-76. https://doi.org/10.1111/j.1745-6622.2010.00262.x

Kaplan, S. N. (2012). Executive compensation and corporate governance in the US: perceptions, facts and challenges (No. w18395). National Bureau of Economic Research. https://www.nber.org/papers/w18395

Krauter, E. (2013). Remuneração de executivos e desempenho financeiro: um estudo com empresas brasileiras. Revista de Educação e Pesquisa em Contabilidade (REPeC), 7(3).

https://doi.org/10.17524/repec.v7i3.988

Kruger, S. D. (2012). Análise da relação entre o EVA, o MVA e outros indicadores de desempenho das empresas da BM\&FBovespa no período de 2000 a 2010. Dissertação de mestrado, Universidade Federal de Santa Catarina, Santa Catarina, Florianópolis, SC, Brasil.

Kruger, S. D., \& Petri, S. M. (2014). New Evidence of Relationship Between Traditional Measures of Performance and Those Based on Value Creation From the Cost of Capital. Revista Universo Contábil, 125143. https://doi.org/10.4270/ruc.2014215

Larcker, D. F., Tayan, B. (2019). CEO compensation: data spotlight. CGRI Quick Guide Series. Corporate Governance Research Initiative. January 2019. https://www.gsb.stanford.edu/facultyresearch/publications/ceo-compensation-data

Lin, D., \& Lin, L. (2014). The interplay between director compensation and CEO compensation. The International Journal of Business and Finance Research, 8(2), 11-26. Available at SSRN: https://ssrn.com/abstract=2322827

Lin, D., Kuo, H. C., \& Wang, L. H. (2013). Chief executive compensation: An empirical study of fat cat CEOs. The International Journal of Business and Finance Research, 7(2), 27-42. Available at SSRN: https://ssrn.com/abstract $=2149110$ 
Lindqvist, J., \& Grunditz, J. (2004). CEO compensation and company performance: An empirical study of the situation in Sweden's listed companies. Master's thesis School of Business, Economics and Law, Goteborg University, Sweden.

Lopes, I. F., Gasparetto, V., Schnorrenberger, D., \& Lunkes, R. J. (2017). Relação do desempenho financeiro e dos riscos operacionais na remuneração de executivos de empresas brasileiras com ADRs. Contabilidade Vista \& Revista, 28(3), 22-52.

https://revistas.face.ufmg.br/index.php/contabilidadevistaerevista/article/view/3416

Lunardi, M. A., Barbosa, E. T., Rodrigues Junior, M. M., Silva, T. P. da, \& Nakamura, W. T. (2017). Criação de Valor no Desempenho Econômico de Empresas Familiares e Não Familiares Brasileiras. Revista Evidenciação Contábil \& Finanças, 5(1), 94-112. https://doi.org/10.18405/recfin20170106

Machado, T. R. B., \& Rogers, P. (2016). Remuneração dos executivos e o desempenho de companhias abertas brasileiras classificadas nos níveis de governança corporativa da BM\&FBOVESPA. Revista Mineira de Contabilidade, 17(1), 5-13. Recuperado de https://revista.crcmg.org.br/rmc/article/view/243

Martins, O. S., \& Júnior, R. V. (2020). Influência da governança corporativa na mitigação de relatórios financeiros fraudulentos. RBGN: Revista Brasileira de Gestão de Negócios, 22(1), 65-84.

https://doi.org/10.7819/rbgn.v22i1.4039

Murphy, K. J. (2009). Compensation structure and systemic risk. USC Marshall School of Business, Working Paper FBE 34-09, p. 1- 13.

Neto, A. A., Lima, F. G., \& de Araújo, A. M. P. (2008). Uma proposta metodológica para o cálculo do custo de capital no Brasil. Revista de Administração-RAUSP, 43(1), 72-83.

https://www.redalyc.org/pdf/2234/223417484006.pdf

Ozkan, N. (2011). CEO compensation and firm performance: An empirical investigation of UK panel data. European Financial Management, 17(2), 260-285. https://doi.org/10.1111/j.1468-036X.2009.00511.x

Pettit, J. (2000). EVA and production strategy. Industrial Management, 42(6), 6-6.

Raithatha, M., \& Komera, S. (2016). Executive compensation and firm performance: Evidence from Indian firms. IIMB Management Review, 28(3), 160-169. https://doi.org/10.1016/.iimb.2016.07.002

Ramana, D. V. (2005). Market value added and economic value added: Some empirical evidences. In 8th Capital Markets Conference, Indian Institute of Capital Markets Paper. http://dx.doi.org/10.2139/ssrn.871404

Roodman, D. (2009). How to do xtabond2: An introduction to difference and system GMM in Stata. The Stata Journal, 9(1), 86-136. https://doi.org/10.1177/1536867X0900900106

Santos, J. O., \& Watanabe, R. (2005). Uma análise da correlação entre o EVA® e o MVA® no contexto das empresas brasileiras de capital aberto. REGE Revista de Gestão, 12(1), 19-32.

https://www.revistas.usp.br/rege/article/view/36507

Shil, N. C. (2009). Performance measures: An application of economic value added. International Journal of Business and Management, 4(3), 169-177. 10.5539/ijbm.v4n3p169

Smirnova, A. S., \& Zavertiaeva, M. A. (2017). Which came first, CEO compensation or firm performance? The causality dilemma in European companies. Research in International Business and Finance, 42, 658673. https://doi.org/10.1016/j.ribaf.2017.07.009

Souza, P. V. S. D., Cardoso, R. L., \& Vieira, S. S. D. C. (2017). Determinantes da remuneração dos executivos e sua relação com o desempenho financeiro das companhias. REAd. Revista Eletrônica de Administração (Porto Alegre), 23(SPE), 4-28. https://doi.org/10.1590/1413-2311.175.63859

Stern, J. (1993). Value and people management. Corporate Finance, 104, 35-37.

Stern, J., Stewart, B., \& Chew, D. (1998). The EVA financial management system. Available at SSRN 6704. https://papers.ssrn.com/sol3/papers.cfm?abstract id=6704 
Stewart, G. B. (1991). The quest for value. New York: Harper and Collins.

Tortella, B. D., \& Brusco, S. (2003). The Economic Value Added (EVA): an analysis of market reaction. Advances in Accounting, 20, 265-290. https://doi.org/10.1016/S0882-6110(03)20012-2

Vieito, J. P., \& Khan, W. A. (2012). Executive compensation and gender: S\&P 1500 listed firms. Journal of Economics and Finance, 36(2), 371-399. https://doi.org/10.1007/s12197-010-9123-1

Vilela, D. L. (2013). Direcionadores de valor econômico agregado para instituições financeiras: um estudo dos principais bancos comerciais no Brasil. Doctoral dissertation, Universidade de São Paulo.

Walbert, L. (1994). The Stern Stewart performance 1000: using Eva ${ }^{\mathrm{TM}}$ to build market value. Journal of Applied Corporate Finance, 6(4), 109-112. https://doi.org/10.1111/j.1745-6622.1994.tb00256.x

Wet, J. H. (2012). Executive compensation and the EVA and MVA performance of South African listed companies. Southern African Business Review, 16(3), 57-80. https://hdl.handle.net/10520/EJC129105

\section{NOTAS}

\section{AGRADECIMENTOS}

À Universidade Federal de Minas Gerais (UFMG), à Universidade Federal de Alfenas (Unifal), ao Instituto Federal de Minas Gerais - Campus Bambuí (IFMG).

\section{CONTRIBUIÇÃO DE AUTORIA}

Concepção e elaboração do manuscrito: N. G. Oliveira, L. K. Vieira, J. V. A. Cunha

Coleta de dados: N. G. Oliveira

Análise de dados: N. G. Oliveira, L. K. Vieira

Discussão dos resultados: N. G. Oliveira, L. K. Vieira, J. V. A. Cunha

Revisão e aprovação: N. G. Oliveira, L. K. Vieira, J. V. A. Cunha

\section{CONJUNTO DE DADOS DE PESQUISA}

O conjunto de dados que dá suporte aos resultados deste estudo não está disponível publicamente.

\section{FINANCIAMENTO}

Não se aplica.

\section{CONSENTIMENTO DE USO DE IMAGEM}

Não se aplica.

\section{APROVAÇÃO DE COMITÊ DE ÉTICA EM PESQUISA \\ Não se aplica.}

\section{CONFLITO DE INTERESSES}

Não se aplica.

\section{LICENÇA DE USO}

Os Direitos Autorais para artigos publicados neste periódico são do autor, com direitos de primeira publicação para a Revista. Em virtude de aparecerem nesta Revista de acesso público, os artigos são de uso gratuito, com atribuições próprias, em aplicações educacionais, de exercício profissional e para gestão pública. A Revista adotou a licença Creative Commons Atribuição 4.0 Internacional - CC BY NC ND. Esta licença permite acessar, baixar (download), copiar, imprimir, compartilhar, reutilizar e distribuir os artigos desde que com a citação da fonte, atribuindo os devidos créditos de autoria. Nesses casos, nenhuma permissão é necessária por parte dos autores ou dos editores. Autores têm autorização para assumir contratos adicionais separadamente, para distribuição não-exclusiva da versão do trabalho publicada nesta revista (ex.: publicar em repositório institucional ou um capítulo de livro).

\section{PUBLISHER}

Universidade Federal de Santa Catarina. Curso de Ciências Contábeis e Programa de Pós-graduação em Contabilidade. Publicação no Portal de Periódicos UFSC. As ideias expressadas neste artigo são de responsabilidade de seus autores, não representando, necessariamente, a opinião dos editores ou da universidade. 


\section{EDITORES}

Carlos Eduardo Facin Lavarda e Suliani Rover

\section{HISTÓRICO}

Recebido em: 23/11/2020 - Revisado por pares em: 12/05/2021 - Reformulado em: 01/08/2021 Recomendado para publicação em: 02/08/2021 - Publicado em: 04/12/2021 